\title{
APLICAÇÃO DE ÁGUA RESIDUÁRIA DE SUINOCULTURA EM SOLO CULTIVADO COM SOJA: COBRE E ZINCO NO MATERIAL ESCOADO E NO SOLO ${ }^{1}$
}

\author{
TATIANE C. DAL BOSCO ${ }^{2}$, SILVIO C. SAMPAIO ${ }^{3}$, MIGUEL A. U. OPAZO ${ }^{4}$, \\ SIMONE D. GOMES ${ }^{5}$, LÚCIA H. P. NÓBREGA ${ }^{5}$
}

\begin{abstract}
RESUMO: O objetivo deste trabalho foi avaliar a poluição difusa referente ao cobre e ao zinco no solo e no material de escoamento superficial quando da aplicação de água residuária de suinocultura (ARS) em solo cultivado com soja, sob condição de chuva simulada. $\mathrm{O}$ experimento foi instalado em Toledo - PR, sendo aplicadas ao solo cinco taxas de ARS $\left(0 ; 50 ; 100 ; 150\right.$ e $200 \mathrm{~m}^{3} \mathrm{ha}^{-1}$ no ciclo), em três repetições por tratamento, divididas em seis aplicações ao longo do ciclo da soja. Foram instaladas calhas coletoras do material escoado e fizeram-se seis simulações de chuva durante o experimento, resultando em seis coletas do material escoado. Ao final do ciclo da soja, foram coletadas amostras de solo em cada uma das parcelas experimentais, em três profundidades, para a determinação do $\mathrm{pH}$, da capacidade de troca de cátions, da matéria orgânica, do cobre e do zinco. Observou-se que houve perda de cobre e de zinco via escoamento superficial e que as maiores concentrações de cobre foram verificadas nas profundidades de 20-40 e 40-60 cm, enquanto o zinco apresentou maior concentração na camada de $0-20 \mathrm{~cm}$ e, ao final do experimento, aumentou nas demais profundidades.
\end{abstract}

PALAVRAS-CHAVE: escoamento superficial, lixiviação de íons, reúso de água.

\section{SWINE WASTEWATER APPLICATION IN SOIL CULTIVATED WITH SOYBEAN: COPPER AND ZINC IN THE RUNOFF MATERIAL AND IN THE SOIL}

\begin{abstract}
The objective of this work was to evaluate the diffuse pollution regarding to the copper and to the zinc in the soil and in the runoff material due to the application of swine wastewater (ARS) in soil cultivated with soybean, under simulated rain condition. The experiment was installed in Toledo - PR, Brazil, and it was applied to the soil five rates of ARS $(0 ; 50 ; 100 ; 150$ and $200 \mathrm{~m}^{3} \mathrm{ha}^{-1}$ in the cycle), in three replications for treatment, divided in six applications along the cycle of the soybean. Gutters were installed gutters to collect the runoff material and it was made six rain simulations during the experiment, resulting in six collections of the runoff. At the end of the soybean cycle, soil samples were collected in each one of the experimental plots, at three depths, for $\mathrm{pH}$ determination, cation exchangeable capacity, organic matter, copper and zinc. It was observed that there were copper and zinc losses through runoff and the largest copper concentrations were verified at 20-40 and 40-60 $\mathrm{cm}$ depths, while the zinc presented larger concentration in the top layer $0-20 \mathrm{~cm}$ and it increased in the other depths.
\end{abstract}

KEYWORDS: runoff, ions leaching, reuse of water.

\section{INTRODUÇÃO}

A região oeste do Paraná é caracterizada pela intensa atividade de suinocultura. O volume significativo de dejetos produzido por grandes plantéis de suínos implica acúmulo do material na propriedade, demandando o desenvolvimento de técnicas de minimização, tratamento e destino final dos resíduos gerados. Uma dessas técnicas consiste no tratamento dos dejetos em biodigestores

\footnotetext{
${ }^{1}$ Extraído da dissertação de mestrado da primeira autora.

${ }^{2}$ Tecnóloga Ambiental, Doutoranda em Engenharia Agrícola, PGEAGRI/CCET, Unioeste, Cascavel - PR, Prof. Msc, Universidade Tecnológica Federal do Paraná, UTFPR, Londrina - PR, Fone (0XX43) 3029.3226, tatidalbosco@ yahoo.com.br

${ }^{3}$ Eng ${ }^{\mathrm{o}}$ Agrícola, Prof. Adjunto, PGEAGRI/CCET, Unioeste, Cascavel - PR.

${ }^{4}$ Estatístico, Prof. Associado, PGEAGRI/CCET, Unioeste, Cascavel - PR.

${ }^{5}$ Eng $^{\mathrm{a}}$ Agrônoma, Profa. Associada, PGEAGRI/CCET, Unioeste, Cascavel - PR.

Recebido pelo Conselho Editorial em: 18-12-2007
}

Aprovado pelo Conselho Editorial em: 21-1-2009

Eng. Agríc., Jaboticabal, v.28, n.4, p.699-709, out./dez. 2008 
e a consequente aplicação da água residuária em solo agricultável, que, de acordo com CERETTA et al. (2005) e CAOVILLA et al. (2005), é uma forma de ciclar e disponibilizar nutrientes às plantas.

No entanto, BARROS et al. (2005) destacaram que as quantidades e as frequências com que os dejetos animais podem ser aplicados ao solo devem estar associadas com o tipo de solo, com a natureza e a composição dos resíduos, com as condições climáticas e com a espécie vegetal cultivada. Essas variáveis devem ser consideradas quando da aplicação de água residuária de suinocultura no solo a fim de evitar a poluição difusa relacionada às perdas de nutrientes por escoamento superficial e lixiviação de íons no solo.

BARROS et al. (2003) evidenciaram que, além da carga orgânica, os dejetos preocupam pela presença de metais pesados, como o cobre e o zinco, que, segundo MARCATO \& LIMA (2005), são adicionados à alimentação dos suínos com o objetivo de prevenir doenças, melhorar a digestão e promover o crescimento.

SILVA et al. (2005c) afirmaram que a erosão hídrica é um dos principais problemas relacionados ao manejo dos solos no Brasil. CARVALHO et al. (2003) complementaram afirmando que algumas áreas localizadas na região Sul já estão em processo de desertificação devido ao processo erosivo. Como consequência desse processo, AMORIN et al. (2001) citaram o transporte de nutrientes, matéria orgânica, sementes e defensivos agrícolas, implicando empobrecimento gradativo dos solos agrícolas, na elevação do custo de produção e, às vezes, resultando no abandono de áreas anteriormente produtivas. Outra consequência são os problemas relacionados à qualidade e à disponibilidade de água em função da poluição e do assoreamento dos cursos d'água.

$\mathrm{Na}$ literatura, quando se pesquisa sobre lixiviação de íons no perfil do solo, é possível encontrar vários trabalhos relacionados à movimentação do nitrato. Entretanto, sobre os metais pesados, as pesquisas ainda são escassas. FREITAS et al. (2004) destacaram que os dejetos de suínos apresentam cobre e zinco em sua composição, e, assim, sua aplicação em doses elevadas pode resultar em acúmulo desses elementos no solo. Esse acúmulo pode acarretar intoxicação não só às plantas, mas também aos integrantes dos demais níveis da cadeia alimentar. Assim, nota-se a importância das investigações da dinâmica dos metais pesados aplicados ao solo via água residuária de suinocultura e a sua movimentação no perfil do solo, como também perdas via escoamento superficial.

O objetivo deste trabalho foi avaliar a poluição difusa, referente ao cobre e ao zinco no solo e no material de escoamento superficial, quando da aplicação de água residuária de suinocultura (ARS) em Latossolo Vermelho distroférrico cultivado com soja, sob condição de chuva simulada.

\section{MATERIAL E MÉTODOS}

O experimento foi conduzido na Fazenda Experimental da PUC/PR, localizada no município de Toledo, oeste do Paraná, durante os meses de novembro de 2006 a abril de 2007. O solo da área experimental é caracterizado como Latossolo Vermelho distroférrico de textura muito argilosa. Na Tabela 1, é apresentada a caracterização do solo antes da implantação do experimento.

TABELA 1. Caracterização inicial do solo da área experimental. Soil initial characterization in the experimental area.

\begin{tabular}{ccccc}
\hline \multirow{2}{*}{ Profundidade } & $\mathrm{pH}\left(\mathrm{CaCl}_{2}\right)$ & $\mathrm{CTC}^{\mathrm{l}}$ & $\mathrm{Cu}$ & $\mathrm{Zn}$ \\
\cline { 3 - 5 } & & $\mathrm{cmol}_{\mathrm{c}} \mathrm{dm}^{-3}$ & \multicolumn{2}{c}{$\mathrm{mg} \mathrm{dm}^{-3}$} \\
\hline $0-20 \mathrm{~cm}$ & 5,28 & 12,49 & 5,31 & 2,24 \\
$20-40 \mathrm{~cm}$ & 4,37 & 11,58 & 5,74 & 1,28 \\
\hline
\end{tabular}

${ }^{1}$ A metodologia utilizada para a determinação da CTC foi de acordo com EMBRAPA (1997). 
$\mathrm{Na}$ área experimental, semeou-se soja, cultivar CD 215, produzida pela Coodetec Cooperativa Central de Pesquisa Agrícola, a qual apresenta ciclo precoce de 115 dias no Paraná. Utilizou-se do sistema de semeadura direta realizada no dia 15 de novembro de 2006, com adubação de $240 \mathrm{~kg} \mathrm{ha}^{-1}$ da fórmula 2-17-17. Em virtude da baixa emergência de plântulas, no dia 28 de novembro de 2006, fez-se nova semeadura manual, que foi considerada como referência para a contagem dos dias após a semeadura (DAS).

Logo após a semeadura realizada no dia 15 de novembro de 2006, foram cravadas e niveladas no solo 15 calhas construídas em chapas de aço galvanizado número 16 de $0,375 \mathrm{~m}^{2}$ de área, dotadas, na extremidade a favor do declive, de dispositivo coletor do escoamento superficial. A área da parcela na qual se aplicou a ARS foi de $1,08 \mathrm{~m}^{2}$. As parcelas foram protegidas por miniestufas (de polietileno e área de $1,08 \mathrm{~m}^{2}$ ) a partir da primeira aplicação de ARS (aos 38 DAS), visando ao controle hidrológico da área. Em dias de sol, eram retiradas pela manhã e recolocadas no entardecer, enquanto em dias chuvosos, permaneciam sobre as parcelas durante o período de incidência da chuva.

A precipitação foi aplicada mediante o simulador de chuvas InfiAsper/UFMS. A intensidade de precipitação foi de $60 \mathrm{~mm} \mathrm{~h}^{-1}$ (SILVA et al., 2005 a e b; PANACHUKI et al., 2006a). As simulações de chuva ocorreram numa frequência quinzenal. Aos 48 (M1), 62 (M2), 76 (M3), 91 (M4) e 104 DAS (M5) aplicaram-se 79; 112; 91; 81 e $65 \mathrm{~mm}$ de chuva, respectivamente, de acordo com LONGO et al. (2006). Aos 118 DAS (M6), fizeram-se testes de infiltração de água no solo, de acordo com metodologia de PANACHUKI et al. (2006b). Sendo assim, a quantidade de chuva variou em função da estabilização da taxa.

A água residuária de suinocultura (ARS) utilizada foi coletada após a passagem por biodigestor, seguido de tanque de sedimentação e lagoa de estabilização, sendo, na saída dessa, o ponto de coleta. A caracterização da ARS foi realizada em três momentos durante o experimento: aos 38; 67 e 111 dias após a semeadura. A caracterização média da ARS é apresentada na Tabela 2.

TABELA 2. Caracterização média da água residuária de suinocultura utilizada durante o experimento. Medium characterization of swine wastewater used in the experiment.

\begin{tabular}{cccccccc}
\hline Parâmetros & $\mathrm{pH}$ & $\mathrm{CE}$ & Turbidez & $\mathrm{DBO}^{1}$ & $\mathrm{DQO}^{2}$ & $\mathrm{Cu}$ & $\mathrm{Zn}$ \\
\cline { 5 - 7 } Unidades & $\left(\mathrm{CaCl}_{2}\right)$ & $\mathrm{dS} \mathrm{m}^{-1}$ & $\mathrm{NTU}$ & \multicolumn{3}{c}{$\mathrm{mg} \mathrm{L}^{-1}$} & \\
\hline Média & 7,73 & 4,89 & 459,33 & 671,04 & $1.444,07$ & 0,20 & 1,17 \\
\hline
\end{tabular}

CE - condutividade elétrica; DBO - demanda bioquímica de oxigênio; DQO - demanda química de oxigênio; $\mathrm{Cu}$ cobre; Zn - zinco. As metodologias para a determinação dos parâmetros apresentados na Tabela seguiram APHA/AWWA/WEF (1998).

Os tratamentos aplicados às parcelas consistiram em cinco taxas de aplicação de ARS: 0; 50; 100; 150 e $200 \mathrm{~m}^{3}$ ha $^{-1}$ no ciclo para T0, T1, T2, T3 e T4, respectivamente. As taxas de ARS foram divididas em seis aplicações: 38; 54; 67; 80; 94 e 111 dias após a semeadura, sendo três repetições por tratamento.

O material escoado foi armazenado em frascos plásticos de $500 \mathrm{~mL}$. As amostras foram refrigeradas durante o deslocamento até o laboratório onde se determinou o teor de cobre e de zinco.

Ao final do ciclo da soja, foram coletadas amostras de solo de cada uma das parcelas experimentais, nas profundidades de $0-20 \mathrm{~cm}, 20-40 \mathrm{~cm}$ e $40-60 \mathrm{~cm}$ para a determinação do $\mathrm{pH}$, da capacidade de troca de cátions (CTC), da matéria orgânica, do cobre e do zinco, de acordo com RAIJ et al. (2001) e EMBRAPA (1997). Essas profundidades foram definidas em função da profundidade efetiva da cultura.

O delineamento estatístico referente ao material de escoamento superficial consistiu em um bifatorial no delineamento inteiramente casualizado, com parcelas subdivididas, com três 
repetições. O fato de as coletas terem sido realizadas ao longo do tempo, implicou realização de análise longitudinal, de acordo com SINGER \& ANDRADE (1986). O delineamento estatístico referente ao $\mathrm{pH}$, à matéria orgânica, à $\mathrm{CTC}$, ao cobre e ao zinco consistiu em um fatorial $5 \times 3$ (cinco tratamentos e três profundidades). Utilizou-se do teste de Tukey $(\mathrm{p}<0,05)$ para a comparação de médias, tanto dos resultados referentes ao solo quanto do escoado, visto que esse teste é o mais indicado quando se trata de análise longitudinal.

Antes de realizar a análise de variância (ANOVA), fez-se análise descritiva dos dados e verificou-se a normalidade dos erros. Para os parâmetros que não apresentaram distribuição normal dos erros, utilizou-se da transformação de Box Cox. As médias obtidas foram comparadas pelo teste de Tukey, a 5\% de significância.

\section{RESULTADOS E DISCUSSÃO}

$\mathrm{Na}$ Tabela 3, é apresentado o resumo da análise de variância do $\mathrm{pH}\left(\mathrm{CaCl}_{2}\right)$ do extrato aquoso do solo, da matéria orgânica e da capacidade de troca de cátions (CTC) em função dos tratamentos com ARS e das profundidades amostradas.

TABELA 3. Valores de $\mathrm{F}$ para $\mathrm{pH}\left(\mathrm{CaCl}_{2}\right)$ do solo, para matéria orgânica $\left(\mathrm{g} \mathrm{dm}^{-3}\right)$ e para capacidade de troca de cátions $\left(\mathrm{cmolc} \mathrm{dm}^{-3}\right)$. F values for $\mathbf{p H}\left(\mathbf{C a C l}_{2}\right)$ of the soil, organic matter $\left(\mathrm{g} \mathrm{dm}^{-3}\right)$ and cation exchange capacity $\left(\mathrm{cmol}_{\mathbf{c}} \mathbf{d m}^{-3}\right)$.

\begin{tabular}{cccc}
\hline Fonte de Variação & pH do Solo & Matéria Orgânica & CTC \\
\hline Tratamento (T) & $1,72^{\text {ns }}$ & $0,54^{\text {ns }}$ & $3,52^{*}$ \\
Profundidade (P) & $19,82^{*}$ & $40,82^{*}$ & $4,17^{*}$ \\
Interação (T x P) & $0,45^{\text {ns }}$ & $0,42^{\text {ns }}$ & $0,72^{\text {ns }}$ \\
\hline C.V. $(\%)$ & 7,61 & 11,81 & 13,53 \\
Média Geral & 4,45 & 32,93 & 13,42 \\
\hline
\end{tabular}

* significativo a 5\% de probabilidade; "ns" não-significativo.

Verifica-se, pela Tabela 3, que, para o $\mathrm{pH}$ e a matéria orgânica, o valor de $\mathrm{F}$ foi significativo para profundidade, enquanto para a CTC, além da profundidade, teve-se também o efeito tratamento. $\mathrm{O}$ coeficiente de variação do $\mathrm{pH}$ indicou homogeneidade dos dados e foi classificado como baixo, uma vez que foi menor que $10 \%$. Os coeficientes de variação da matéria orgânica e da CTC foram classificados como médios, visto que estiveram compreendidos no intervalo de 10 a 20\% (PIMENTEL GOMES, 2000).

$\mathrm{Na}$ Tabela 4, é apresentado o resultado do teste de comparação de médias do pH do extrato aquoso do solo e da matéria orgânica, de acordo com as profundidades amostradas.

TABELA 4. Teste de comparação de médias do $\mathrm{pH}\left(\mathrm{CaCl}_{2}\right)$ do solo e da matéria orgânica $\left(\mathrm{g} \mathrm{dm}^{-3}\right)$ nas profundidades amostradas. Average comparison test for soil $\mathbf{p H}\left(\mathrm{CaCl}_{2}\right)$ and for organic matter $\left(\mathrm{g} \mathrm{dm}^{-3}\right)$ in the soil layers.

\begin{tabular}{cccc}
\hline \multirow{2}{*}{ Tratamentos } & \multicolumn{3}{c}{ Profundidades $(\mathrm{cm})$} \\
\cline { 2 - 4 } & $0-20$ & $20-40$ & $40-60$ \\
\hline $\mathrm{pH}$ & $4,88 \mathrm{~b}$ & $4,33 \mathrm{a}$ & $4,14 \mathrm{a}$ \\
Matéria orgânica & $38,78 \mathrm{c}$ & $33,95 \mathrm{~b}$ & $26,06 \mathrm{a}$ \\
\hline
\end{tabular}

Letras minúsculas iguais na linha não diferem entre si, de acordo com o Teste de Tukey, a 5\% de significância.

De acordo com a Tabela 4, o $\mathrm{pH}$ do extrato aquoso do solo foi maior na profundidade de $0-20 \mathrm{~cm}$ do que na profundidade de $20-40 \mathrm{~cm}$ e de $40-60 \mathrm{~cm}$, que, por sua vez, não diferiram estatisticamente entre si $(\mathrm{p}<0,05)$. Verifica-se, ainda, que, segundo MALAVOLTA et al. (2002), os valores de $\mathrm{pH}$ não se enquadraram na faixa ideal de $\mathrm{pH}$ do solo tida como 6,0 e 6,5. Entretanto, esse comportamento não pode ser diretamente relacionado à aplicação de ARS no solo, uma vez que o 
pH das parcelas-testemunha e do solo, quando da caracterização inicial (Tabela 1), também apresentaram valores inferiores a 6,0. Observa-se que o $\mathrm{pH}$ da camada de $0-20 \mathrm{~cm}$ antes da implantação do experimento era de 5,28 e que, ao final do ciclo da cultura, variou entre 4,59 e 5,15.

LOPES (1998) afirmou que as leguminosas liberam íons de hidrogênio em sua rizosfera quando estão fixando ativamente o nitrogênio atmosférico, o que pode explicar a diminuição do $\mathrm{pH}$ do solo ao final do experimento, em comparação com a caracterização inicial. O autor explicou que, no processo de nitrificação, há a conversão do íon amônio a nitrato, e íons hidrogênio são liberados, promovendo a acidificação do solo. O mesmo ocorre quando da decomposição da matéria orgânica.

Na Tabela 4, observa-se que o teor de matéria orgânica variou em função da profundidade, o que, para MALAVOLTA et al. (2002), é um comportamento muito comum. A concentração apresentada na profundidade de $0-20 \mathrm{~cm}$ foi maior e apresentou diferença significativa em relação às demais, o que pode estar relacionado ao maior acúmulo de resíduo vegetal nessa camada. Observa-se, na Tabela 2, que a concentração média de DBO presente na ARS aplicada foi de $671,04 \mathrm{mg} \mathrm{L}^{-1}$, o que resultou na adição de 33,55; 67,10; 100,66 e 134,21 $\mathrm{kg} \mathrm{ha}^{-1}$ nos tratamentos T1, T2, T3 e T4, respectivamente, não implicando diferença significativa entre tratamentos da quantidade de matéria orgânica presente no solo, ao final do experimento.

$\mathrm{Na}$ Tabela 5, são apresentadas as médias da CTC do solo por tratamento, em função das profundidades amostradas.

TABELA 5. Teste de comparação de médias referentes à CTC $\left(\mathrm{cmol}_{\mathrm{c}} \mathrm{dm}^{-3}\right)$ do solo, de acordo com os tratamentos com água residuária de suinocultura e as profundidades amostradas. Average comparison test for soil cation exchange capacity $\left(\mathrm{cmol}_{\mathrm{c}} \mathrm{dm}^{-3}\right)$ for the treatments and soil layers.

\begin{tabular}{cccccc}
\hline Tratamentos & T0 & T1 & T2 & T3 & T4 \\
\hline Médias & $15,09 \mathrm{~b}$ & $14,01 \mathrm{ab}$ & $12,19 \mathrm{a}$ & $12,82 \mathrm{ab}$ & $13,01 \mathrm{ab}$ \\
\hline Profundidades $(\mathrm{cm})$ & $0-20$ & & $20-40$ & & $40-60$ \\
\hline Médias & $12,40 \mathrm{a}$ & & $14,29 \mathrm{~b}$ & \multicolumn{1}{c}{$13,59 \mathrm{ab}$} \\
\hline
\end{tabular}

Letras minúsculas iguais na linha não diferem entre si, de acordo com o Teste de Tukey $(\mathrm{p}<0,05)$. T0, T1, T2, T3 e T4 = $0 ; 50 ; 100 ; 150$ e $200 \mathrm{~m}^{3}$ ha $^{-1}$ de água residuária de suinocultura, respectivamente.

Observa-se, na Tabela 5, que o T2 foi o tratamento que apresentou menor CTC, sem diferir estatisticamente $(\mathrm{p}<0,05)$ do T1, T3 e T4. A testemunha (T0), que diferiu estatisticamente apenas de T2, apresentou maior CTC. As camadas mais profundas, de $20-40 \mathrm{~cm}$ e de $40-60 \mathrm{~cm}$, foram as que apresentaram maior CTC. A profundidade de $0-20 \mathrm{~cm}$ não diferiu estatisticamente $(\mathrm{p}<0,05)$ da profundidade de 40-60 $\mathrm{cm}$ e foi a camada que apresentou menor CTC. Considerando a baixa concentração de matéria orgânica na água residuária de suinocultura utilizada no estudo, provavelmente ocorreu lixiviação dos íons presentes no solo para as camadas mais profundas, resultando em maior CTC para as profundidades de $20-40 \mathrm{~cm}$ e de $40-60 \mathrm{~cm}$.

Na Tabela 6, apresenta-se o resumo da análise de variância da concentração de cobre e zinco no material escoado, considerando os tratamentos com ARS aplicados durante o desenvolvimento da cultura da soja.

Na Tabela 6, observa-se que, no segundo estágio da análise de variância do cobre no material escoado, o valor da estatística $\mathrm{F}$ foi significativo para o efeito interação, enquanto para o zinco, o valor de $\mathrm{F}$ foi significativo apenas para o momento, a 5\% de significância. Os coeficientes de variação do cobre e do zinco foram classificados como muito altos, o que indica que os dados são heterogêneos (PIMENTEL GOMES, 2000).

Na Tabela 7, é apresentado o resultado do teste de comparação das médias da concentração de cobre no material escoado, levando em consideração os tratamentos com ARS aplicados e os momentos de coleta. 
TABELA 6. Resumo da análise de variância do cobre e do zinco ( $\mathrm{mg} \mathrm{L}^{-1}$ ) no material escoado, considerando os tratamentos com água residuária de suinocultura durante $\mathrm{o}$ desenvolvimento da cultura da soja. Copper and zinc $\left(\mathbf{m g ~ L}^{-1}\right)$ analysis of variance summarize in runoff material considering the treatments with swine wastewater in the development of the soy culture.

\begin{tabular}{|c|c|c|c|c|c|c|c|c|c|}
\hline \multirow{3}{*}{ Fonte de Variação } & \multicolumn{5}{|c|}{ Cobre } & \multicolumn{4}{|c|}{ Zinco } \\
\hline & \multirow{2}{*}{$\mathrm{gl}$} & \multicolumn{2}{|c|}{$1^{0}$ estágio } & \multicolumn{2}{|c|}{$2^{-}$estágio } & \multicolumn{2}{|c|}{$1^{0}$ estágio } & \multicolumn{2}{|c|}{$2^{\underline{0}}$ estágio } \\
\hline & & $\mathrm{F}$ & $\mathrm{Fc}$ & $\mathrm{gl}$ & Fc (Box) & $\mathrm{F}$ & $\mathrm{Fc}$ & $\mathrm{gl}$ & Fc (Box) \\
\hline Tratamento (T) & 4 & 14,04 & $3,48^{*}$ & 4 & $3,48^{*}$ & 3,28 & $3,48^{\mathrm{ns}}$ & 4 & $3,48^{\mathrm{ns}}$ \\
\hline Erro (1) & 10 & & & 10 & & & & 10 & \\
\hline Momento (M) & 5 & 80,29 & $2,71^{*}$ & 1 & $4,96^{*}$ & 13,17 & $2,71^{*}$ & 1 & $4,96^{*}$ \\
\hline Interação (T x M) & 20 & 12,86 & $1,79^{*}$ & 4 & $3,48^{*}$ & 1,67 & $1,79^{\mathrm{ns}}$ & 4 & $3,48^{\mathrm{ns}}$ \\
\hline C.V. geral $(\%)$ & 56,81 & & & & & 69,28 & & & \\
\hline Média Geral & 0,05 & & & & & 0,50 & & & \\
\hline
\end{tabular}

TABELA 7. Teste de comparação de médias da concentração de cobre $\left(\mathrm{mg} \mathrm{L}^{-1}\right)$ no material escoado, em função dos tratamentos com água residuária de suinocultura e dos momentos de coleta. Average comparison test for concentration of copper $\left(\mathrm{mg} \mathrm{L}^{-1}\right)$ in the runoff material due to the treatments with swine wastewater and the sampling time.

\begin{tabular}{llllllc}
\hline & \multicolumn{7}{c}{ Momentos } \\
\cline { 2 - 7 } & \multicolumn{1}{c}{ M1 } & \multicolumn{1}{c}{ M2 } & \multicolumn{1}{c}{ M3 } & \multicolumn{1}{c}{ M4 } & \multicolumn{1}{c}{ M5 } & M6 \\
\hline T0 & $0,0700 \mathrm{Ac}$ & $0,0033 \mathrm{Aa}$ & $0,0267 \mathrm{Aab}$ & $0,0267 \mathrm{ABab}$ & $0,0433 \mathrm{Ab}$ & $0,0133 \mathrm{Aa}$ \\
T1 & $0,0700 \mathrm{Ad}$ & $0,0167 \mathrm{Aa}$ & $0,0333 \mathrm{ABab}$ & $0,0433 \mathrm{BCbc}$ & $0,0633 \mathrm{BCcd}$ & $0,0167 \mathrm{Aa}$ \\
T2 & $0,0700 \mathrm{Ac}$ & $0,0467 \mathrm{Babc}$ & $0,0367 \mathrm{ABab}$ & $0,0400 \mathrm{ABCab}$ & $0,0533 \mathrm{ABbc}$ & $0,0233 \mathrm{Aa}$ \\
T3 & $0,0767 \mathrm{ABc}$ & $0,0867 \mathrm{Cc}$ & $0,0367 \mathrm{ABa}$ & $0,0467 \mathrm{Cab}$ & $0,0667 \mathrm{BCbc}$ & $0,0300 \mathrm{Aa}$ \\
T4 & $0,0900 \mathrm{Bbc}$ & $0,1100 \mathrm{Dc}$ & $0,0467 \mathrm{Ba}$ & $0,0233 \mathrm{Aa}$ & $0,0800 \mathrm{Cb}$ & $0,0300 \mathrm{Aa}$ \\
\hline
\end{tabular}

Letras minúsculas iguais na mesma linha e letras maiúsculas iguais na mesma coluna correspondem a médias iguais, de acordo com o Teste de Tukey, a 5\% de significância. T0, T1, T2, T3 e T4 $=0 ; 50 ; 100 ; 150$ e $200 \mathrm{~m}^{3}$ ha $^{-1}$ de água residuária de suinocultura, respectivamente. M1, M2, M3, M4, M5 e M6 $=48 ; 62 ; 76 ; 91 ; 104$ e 118 dias após a semeadura, respectivamente.

Verifica-se, na Tabela 7, que, de forma geral, a maior taxa de aplicação de ARS no solo (T4) foi o tratamento que apresentou maior concentração de cobre no material escoado para os momentos estudados, exceto para M4 e M6. No entanto, se considerado o padrão de lançamento de efluentes previsto na Resolução 357/2005 do CONAMA (BRASIL, 2005), é possível observar que, mesmo para o tratamento T4, a concentração de cobre no material escoado encontra-se abaixo do limite máximo estabelecido (1,0 $\mathrm{mg} \mathrm{L}^{-1}$ de cobre dissolvido).

Ainda analisando a Tabela 7, observa-se que, para todos os tratamentos, o M6 e o M1 foram os momentos de coleta em que se observaram as menores e as maiores perdas de cobre no material escoado, respectivamente. Tal comportamento condiz com os resultados obtidos por BERTOL (2005), que constatou que as chuvas iniciais tiveram maior efeito na transferência do cobre para a enxurrada superficial, o que pode estar associado ao teor de matéria orgânica, uma vez que, quanto maior o teor de matéria orgânica do solo, tanto maior é a capacidade de adsorção de metais adicionados como adubo e, portanto, menor a quantidade apresentada na solução passível de ser escoada. Assim, constata-se que a adição gradativa de matéria orgânica no decorrer do experimento resultou na adsorção do cobre aplicado via ARS, de modo que, na última coleta, a concentração desse elemento foi menor e não diferiu entre os tratamentos. Entretanto, vale destacar que o comportamento do cobre deve ser investigado a longo prazo, uma vez que foi identificado na água de escoamento superficial e foi maior para as maiores taxas de ARS aplicadas. 
$\mathrm{Na}$ Tabela 8, é apresentado o resumo do teste de comparação de médias do zinco no material escoado em função dos momentos de coleta.

TABELA 8. Teste de comparação de médias da concentração de zinco ( $\mathrm{mg} \mathrm{L}^{-1}$ ) no material escoado, em função dos momentos de coleta. Average comparison test for zinc concentration $\left(\mathrm{mg} \mathrm{L}^{-1}\right)$ in the runoff material due to sampling time.

\begin{tabular}{ccccccc}
\hline Momentos & M1 & M2 & M3 & M4 & M5 & M6 \\
\hline Médias & $0,82 \mathrm{c}$ & $0,27 \mathrm{a}$ & $0,71 \mathrm{bc}$ & $0,46 \mathrm{ab}$ & $0,51 \mathrm{ab}$ & $0,26 \mathrm{a}$ \\
\hline
\end{tabular}

Letras minúsculas iguais na linha não diferem entre si, de acordo com o Teste de Tukey, a 5\% de significância. M1, M2, M3, M4, M5 e M6 = 48; 62; 76; 91; 104 e 118 dias após a semeadura, respectivamente.

Na Tabela 8, verifica-se que as maiores concentrações no material escoado ocorreram nos momentos M1 e M3 (que não diferiram entre si), seguidos de M4 e M5 (que foram iguais estatisticamente a 5\% de significância). Considerando que a água utilizada na simulação de chuva apresentou, em média, $0,07 \mathrm{mg} \mathrm{L}^{-1}$ de zinco e que as concentrações médias verificadas no material escoado para os tratamentos foram superiores a esse valor, pode-se afirmar que houve perda de zinco via escoamento superficial, seja em função da aplicação de ARS, seja do arraste desse elemento contido naturalmente no solo.

A resolução 357/2005 do CONAMA (BRASIL, 2005) prevê para o lançamento de efluentes, concentração máxima de $5,0 \mathrm{mg} \mathrm{L}^{-1}$ de zinco. Se considerado esse padrão, observa-se que as perdas do elemento em todos os tratamentos e momentos se enquadram no valor máximo permitido. Entretanto, se considerado o limite máximo para a classificação de um curso d'água nas classes 1 ou 2 (água doce), cujo padrão é $0,18 \mathrm{mg} \mathrm{L}^{-1}$, dependendo da vazão do curso d'água e da concentração de zinco no rio, a água de escoamento superficial pode representar potencial contaminante, vindo a superar a concentração máxima estabelecida para o enquadramento nessas classes.

Na Tabela 9, é apresentado o resumo da análise de variância do cobre e do zinco no solo, em função dos tratamentos com ARS e das profundidades amostradas.

TABELA 9. Valores de F para cobre e zinco no solo $\left(\mathrm{mg} \mathrm{dm}^{-3}\right)$ em função dos tratamentos com água residuária de suinocultura e das profundidades amostradas. Copper and zinc $\mathbf{F}$ values in the soil $\left(\mathrm{mg} \mathrm{dm}^{-3}\right)$ in function of the treatments with swine wastewater and the depths sampling.

\begin{tabular}{ccc}
\hline Fonte de Variação & Cobre & Zinco \\
\hline Tratamento (T) & $1,51^{\text {ns }}$ & $1,68^{\text {ns }}$ \\
Profundidade (P) & $14,61^{*}$ & $10,32^{*}$ \\
Interação (T x P) & $0,30^{\text {ns }}$ & $0,72^{\text {ns }}$ \\
\hline C.V.(\%) & 14,04 & 52,74 \\
Média Geral & 4,11 & 3,11 \\
\hline
\end{tabular}

* significativo a 5\% de probabilidade; "ns" não-significativo. Utilizou-se da transformação de Box Cox para os dados de zinco no solo (lambda $=-0,212116$ ).

Verifica-se, na Tabela 9, que o valor de $\mathrm{F}$ foi significativo para a profundidade na análise de cobre e de zinco. O coeficiente de variação do cobre foi classificado como médio por estar compreendido no intervalo de 10 a $20 \%$, representando homogeneidade média dos dados, enquanto o do zinco foi classificado como muito alto visto que foi superior a $30 \%$, representando dados heterogêneos (PIMENTEL GOMES, 2000).

Na Tabela 10, é apresentado o resultado do teste de comparação das médias da concentração de cobre no solo. 
TABELA 10. Teste de comparação de médias do cobre e do zinco $\left(\mathrm{mg} \mathrm{dm}^{-3}\right)$ no solo. Average comparison test for concentration of copper and zinc $\left(\mathrm{mg} \mathrm{dm}^{-3}\right)$ in the soil.

\begin{tabular}{ccccccc}
\hline Parâmetros & \multicolumn{3}{c}{ Cobre } & \multicolumn{3}{c}{ Zinco } \\
\hline Profundidades $(\mathrm{cm})$ & $0-20$ & $20-40$ & $40-60$ & $0-20$ & $20-40$ & $40-60$ \\
Médias & $3,47 \mathrm{a}$ & $4,33 \mathrm{~b}$ & $4,53 \mathrm{~b}$ & $4,40 \mathrm{~b}$ & $2,66 \mathrm{a}$ & $2,27 \mathrm{a}$ \\
\hline
\end{tabular}

Letras minúsculas iguais na linha não diferem entre si de acordo com o Teste de Tukey, a $5 \%$ de significância. As médias de zinco são as obtidas das observações originais seguidas das letras obtidas na comparação de médias com a transformação de Box Cox (lambda = -0,212116).

Nota-se, na Tabela 10, que as maiores concentrações de cobre no solo ocorreram nas profundidades de $20-40 \mathrm{~cm}$ e de $40-60 \mathrm{~cm}$ (porém essas não diferiram entre si a $5 \%$ de significância) para todos os tratamentos, inclusive a testemunha. Dessa maneira, embora esses resultados preocupem por caracterizar maiores concentrações nas maiores profundidades do solo e, por consequência, possibilidade de contaminação da água subterrânea, não se pode afirmar que essas maiores concentrações de cobre observadas nas profundidades de $20-40 \mathrm{~cm}$ e de $40-60 \mathrm{~cm}$ estão associadas à aplicação da ARS no solo, visto que a concentração desse elemento no solo, quando da caracterização inicial, também foi menor para a profundidade de $0-20 \mathrm{~cm}\left(5,31 \mathrm{mg} \mathrm{dm}^{-3}\right)$ em comparação à profundidade de $20-40 \mathrm{~cm}\left(5,74 \mathrm{mg} \mathrm{dm}^{-3}\right)$. Esse comportamento pode estar associado ao tratamento aplicado à água residuária utilizada que apresentava baixos teores de cobre, zinco e também matéria orgânica.

Esses resultados corroboram os obtidos por BERTOL (2005), que também não verificou diferença estatística entre os tratamentos com ARS aplicados para as concentrações de cobre no solo. O autor afirmou, ainda, que a perda desse elemento é maior por superfície que por subsuperfície, o que também pode ser constatado no presente trabalho, tendo em vista que houve perda de cobre via escoamento superficial, mas não foi verificada perda do elemento por lixiviação. Assim, embora não seja possível afirmar que a ARS teve efeito sobre as maiores concentrações de cobre em 20-40 cm e 40-60 cm, esse comportamento indica necessidade de estudos a longo prazo para verificar o potencial poluidor difuso das perdas de cobre por lixiviação quando da aplicação de ARS.

OLIVEIRA \& MATTIAZZO (2001) explicaram que a imobilidade do cobre normalmente é atribuída à formação de complexos organo-metálicos estáveis e de baixa solubilidade, mas que, além da complexação com substâncias orgânicas, pode ocorrer sua ligação com frações não-trocáveis do solo, como, por exemplo, óxidos de ferro e manganês. Os autores afirmaram, ainda, que a maior ou a menor mobilidade dos metais pesados é determinada pelos atributos do solo, tais como teores e tipos de argila, $\mathrm{pH}$, capacidade de troca de cátions e teor de matéria orgânica que influenciarão nas reações de adsorção/dessoração, precipitação/dissolução, complexação e oxirredução.

GOMES et al. (2001) constataram baixa mobilidade do cobre no solo e afirmaram que esse elemento é, entre os metais pesados, um dos mais fortemente adsorvido pelo solo. PIERANGELI et al. (2004) complementaram dizendo que elementos na matriz do solo, como óxidos de ferro e alumínio, matéria orgânica e fósforo, são capazes de reter fortemente o cobre, tornando-o altamente imóvel no solo. A menor concentração do cobre na profundidade de $0-20 \mathrm{~cm}$ pode estar associada ao processo de perdas via escoamento superficial, visto que essa camada está mais diretamente relacionada ao processo de arraste e também à remoção desse elemento por parte das plantas. Além disso, considerando o comportamento do $\mathrm{pH}$ e da matéria orgânica, o que pode ter ocorrido foi maior adsorção do cobre aos coloides orgânicos do solo, diminuindo sua concentração na solução do solo, implicando menor teor quando da análise da solução desse solo em laboratório.

Comparando-se os resultados referentes ao cobre no solo com os da CTC, apresentada na Tabela 5, verifica-se o mesmo comportamento para ambos os parâmetros. Assim, pode-se inferir que o comportamento do cobre no solo está relacionado ao da CTC, uma vez que, de acordo com LOPES (1998), quanto maior o valor da CTC do solo, maior o número de cátions que ele pode 
reter. Dessa maneira, considerando que as profundidades de $20-40 \mathrm{~cm}$ e de $40-60 \mathrm{~cm}$ apresentaram CTC maior que na profundidade de $0-20 \mathrm{~cm}$, como consequência, foram capazes de reter maior quantidade do cátion $\mathrm{Cu}^{2+}$. Além disso, de acordo com WARNCKE \& BARBER (1972), o

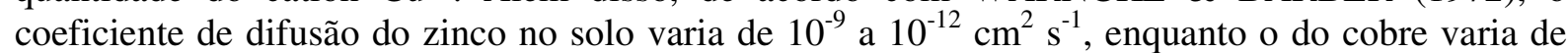
$1-55 \times 10^{-7} \mathrm{~cm}^{2} \mathrm{~s}^{-1}$, caracterizando o menor potencial do zinco em se movimentar no solo em relação ao cobre.

De acordo com EMBRAPA (2004), quando o teor de cobre no solo é alto, como é o caso do solo deste estudo (conforme Tabela 1), a indicação de adubação desse elemento para a cultura da soja é de $0,5 \mathrm{~kg} \mathrm{ha}^{-1}$. Observa-se que o teor desse micronutriente aplicado via ARS até o final do ciclo da soja foi de $0,01 \mathrm{~kg} \mathrm{ha}^{-1} ; 0,02 \mathrm{~kg} \mathrm{ha}^{-1} ; 0,03 \mathrm{~kg} \mathrm{ha}^{-1}$ e $0,04 \mathrm{~kg} \mathrm{ha}^{-1}$ para o T1, T2, T3 e T4, respectivamente. Sendo assim, verifica-se que as quantidades de cobre aplicadas via ARS foram inferiores à indicação máxima para o solo, e a redução dos teores desse elemento ao final do experimento (em comparação à caracterização inicial) pode estar associada à remoção por parte da cultura da soja.

Verifica-se, na Tabela 10, que a profundidade de $0-20 \mathrm{~cm}$ foi a que apresentou maior teor de zinco no solo, diferindo-se das profundidades de $20-40 \mathrm{~cm}$ e $40-60 \mathrm{~cm}$, a $5 \%$ de significância. Comportamento semelhante foi verificado por QUEIROZ et al. (2004), quando da aplicação de ARS no solo. De acordo com os autores, o zinco mostrou movimentação reduzida dentro das camadas do solo, mantendo concentrações mais elevadas na profundidade de $0-20 \mathrm{~cm}$.

A esse comportamento pode-se relacionar a existência de maior teor de matéria orgânica no solo na profundidade de 0-20 cm em comparação a 20-40 cm e 40-60 cm. De acordo com BERTOL (2005), o húmus tem-se mostrado capaz de imobilizar metais pesados que estejam presentes no solo por meio da adsorção desses elementos pelos diferentes componentes do húmus.

Observa-se que a concentração de zinco no solo, quando da caracterização inicial do experimento (Tabela 1), foi de $2,24 \mathrm{mg} \mathrm{dm}^{-3}$ e $1,28 \mathrm{mg} \mathrm{dm}^{-3}$ para a profundidade de $0-20 \mathrm{~cm}$ e 20-40 cm, respectivamente. Nota-se, portanto, que, ao final do experimento, para todos os tratamentos e para as profundidades de $0-20 \mathrm{~cm}$ e $20-40 \mathrm{~cm}$, a concentração de zinco aumentou no solo. O aumento da concentração de zinco na profundidade de $20-40 \mathrm{~cm}$, em relação à caracterização prévia da área, pode ser atribuída ao fato de que, quando há mais de um cátion presente na solução (ARS), há menor disponibilidade de sítios de adsorção para ambos, o que facilita sua presença na solução do solo e, consequentemente, seu deslocamento (MARTINEZ et al., 2001).

A EMBRAPA (2004) estabeleceu que, para solos com elevado teor de zinco, como é o caso do solo deste estudo, a adição de zinco para o cultivo da soja deve ser de $4 \mathrm{~kg} \mathrm{ha}^{-1}$. A ARS forneceu ao solo e à planta, em termos de zinco, $0,0585 \mathrm{~kg} \mathrm{ha}^{-1} ; 0,1170 \mathrm{~kg} \mathrm{ha}^{-1} ; 0,1755 \mathrm{~kg} \mathrm{ha}^{-1} \mathrm{e}$ $0,2340 \mathrm{~kg} \mathrm{ha}^{-1}$ para T1, T2, T3 e T4, respectivamente.

\section{CONCLUSÕES}

Houve efeito da aplicação de ARS nas perdas de cobre via escoamento superficial, e essas podem influenciar na qualidade das águas superficiais. As maiores concentrações de cobre no solo foram verificadas nas profundidades de 20-40 e 40-60 cm, mas esse comportamento não foi associado à aplicação de ARS. As maiores concentrações de zinco no solo foram observadas na camada de 0-20 cm e, ao final do experimento, constatou-se aumento das concentrações desse elemento para todos os tratamentos, nas profundidades de 0-20 e 20-40 cm.

\section{AGRADECIMENTOS}

Ao Conselho Nacional de Desenvolvimento Científico e Tecnológico (CNPq), pelo financiamento do projeto de pesquisa e concessão da bolsa de mestrado. 


\section{REFERÊNCIAS}

APHA/AWWA/WEF. AMERICAN PUBLIC HEALTH ASSOCIATION. Standard methods for the examination of water and wastewater. $20^{\text {th }}$ ed. Washington, 1998. $1.193 \mathrm{p}$.

AMORIN, R.S.S.; SILVA, D.D.; PRUSKI, F.F.; MATOS, A.T. Influência da declividade do solo e da energia cinética de chuvas simuladas no processo de erosão entre sulcos. Revista Brasileira de Engenharia Agrícola e Ambiental, Campina Grande, v.5, n.1, p.124-30, 2001.

BARROS, F.M.; MARTINEZ, M.A.; NEVES, J.C.L.; MATOS, A.T.; SILVA, D.D. Características químicas do solo influenciadas pela adição de água residuária da suinocultura. Revista Brasileira de Engenharia Agrícola e Ambiental, Campina Grande, v. 9, p.47-51, 2005. Suplemento

BARROS, L.S.S.; AMARAL, L.A.; LUCAS JÚNIOR, J. Poder poluente de águas residuárias de suinocultura após utilização de um tratamento integrado. Brazilian Journal of Veterinary Research and Animal Science, São Paulo, v.40, n.2, p.126-35, 2003. Suplemento

BERTOL, O. J. Contaminação da água de escoamento superficial e da água perolada pelo efeito de adubação mineral e adubação orgânica em sistema de semeadura direta. 2005. 209 f. Tese (Doutorado em Engenharia Florestal) - Universidade Federal do Paraná, Curitiba, 2005.

BRASIL. Ministério do Meio Ambiente. Conselho Nacional do Meio Ambiente. Resolução no 357 de 17 de março de 2005. Diário oficial da União, Brasília, 18 mar. 2005.

CAOVILLA, F.A.; SAMPAIO, S.C.; PEREIRA, J.O.; VILAS BOAS, M.A.; GOMES, B.M.; FIGUEIREDO, A.C. Lixiviação de nutrientes provenientes de águas residuárias em colunas de solo cultivado com soja. Revista Brasileira de Engenharia Agrícola e Ambiental, Campina Grande, v. 9, p.283-7, 2005. Suplemento

CARVALHO, D.F.; MONTEBELLER, C.A.; CRUZ, E.S.; LANA, A.M.Q.; SILVA, W.A. Efeito da cobertura morta e do preparo do terreno nas perdas de solo e água em um Argissolo VermelhoAmarelo. Engenharia na Agricultura, Viçosa, v.11, p.1-4, jan./dez., 2003.

CERETTA, C.A.; BASSO, C.J.; VIEIRA, F.C.B.; HERBES, M.G.; MOREIRA, I.C.L.; BERWANGER, A.L. Dejeto líquido de suínos: I - perdas de nitrogênio e fósforo na solução escoada na superfície do solo, sob plantio direto. Ciência Rural, Santa Maria, v.35, n.6, p.1.2961.304, 2005.

EMBRAPA. EMPRESA BRASILEIRA DE PESQUISA AGROPECUÁRIA. Centro Nacional de Pesquisas de Solos. Manual de métodos de análise de solo. 2.ed. Rio de Janeiro, 1997. 221 p.

EMBRAPA. EMPRESA BRASILEIRA DE PESQUISA AGROPECUÁRIA. Tecnologias de produção de soja - Paraná 2005. Londrina, 2004. 224 p.

FREITAS, W.S.; OLIVEIRA, R.A.; PINTO, F.A.; CECON, P.R.; GALVÃO, J.C.C. Efeito da aplicação de águas residuárias de suinocultura sobre a produção do milho para silagem. Revista Brasileira de Engenharia Agrícola e Ambiental, Campina Grande, v.8, n.1, p.120-5, 2004.

GOMES, P.C.; FONTES, M.P.F.; SILVA, A.G.; MENDONÇA, E.S.; NETTO, A.R. Selectivity sequence and competitive adsorption of heavy metals by brazilian soils. Soil Science Society of America Journal, Madison, v.65, n.4, p.1.115-21, 2001.

LONGO, A.J.; SAMPAIO, S.C.; SUSZEK, M. Equação de chuvas intensas e precipitação provável para o município de Cascavel - PR. Varia Scientia, Cascavel, v.6, n.12, p.16-30, 2006.

LOPES, A.S. Manual internacional de fertilidade do solo. Piracicaba: POTAFÓS, 1998. 177 p.

MALAVOLTA, E.; PIMENTEL GOMES, F.; ALCARDE, J.C. Adubos e adubações. São Paulo: Nobel, 2002. 199 p.

MARCATO, S.M.; LIMA, G.J.M.M. Efeito da restrição alimentar como redutor do poder poluente dos dejetos suínos. Revista Brasileira de Zootecnia, Viçosa, v.34, n.3, p.855-63, 2005. 
MARTINEZ, M.A.; RAMOS, V.B.N.; MATOS, A.T.; OLIVEIRA, R.A.; COSTA, S.N. Influência da competição catiônica nos valores de fator de retardamento e coeficiente de dispersão-difusão de zinco e cobre no solo. Revista Brasileira de Engenharia Agrícola e Ambiental, Campina Grande, v.5, n.2, p.211-15, 2001.

OLIVEIRA, F.C.; MATTIAZZO, M.E. Mobilidade de metais pesados em um Latossolo Amarelo distrófico tratado com lodo de esgoto e cultivado com cana-de-açúcar. Scientia Agrícola, Piracicaba, v.58, n.4, p.807-12, 2001.

PANACHUKI, E.; ALVES SOBRINHO, T.; VITORINO, A.C.T.; CARVALHO, D.F. de; URCHEI, M.A. Parâmetros físicos do solo e erosão hídrica sob chuva simulada, em área de integração agricultura-pecuária. Revista Brasileira de Engenharia Agrícola e Ambiental, Campina Grande, v.10, n.2, p.261-8, 2006a.

PANACHUKI, E.; ALVES SOBRINHO, T.; VITORINO, A.C.T.; CARVALHO, D.F. de; URCHEI, M.A. Avaliação da infiltração de água no solo, em sistema de integração agricultura-pecuária, com uso de infiltrômetro de aspersão portátil. Acta Science Agronomy, Maringá, v.28, n.1, p.129-37, 2006b.

PIERANGELI, M.A.P.; GUILHERME, L.R.G.; CURI, N.; ANDERSON, S.J.; LIMA, J.M. Adsorção e dessorção de cádmio, cobre e chumbo por amostras de latossolos pré-tratadas com fósforo. Revista Brasileira de Ciência do Solo, v.28, n.2, p.377-84, 2004.

PIMENTEL GOMES, F. Curso de estatística experimental. 14.ed. Piracicaba: Degaspari, 2000. $477 \mathrm{p}$.

QUEIROZ, F.M.; MATOS, A.T.; PEREIRA, O.G.; OLIVEIRA, R.A. Características químicas de solo submetido ao tratamento com esterco líquido de suínos e cultivado com gramíneas forrageiras. Ciência Rural, Santa Maria, v.34, n.5, p.1.487-92, 2004.

RAIJ, B.V.; ANDRADE, J.C.; CANTARELLA, H.; QUAGGIO, J.A. Análise química para avaliação da fertilidade de solos tropicais. Campinas: Instituto Agronômico, 2001. 285 p.

SILVA, C.G.; ALVES SOBRINHO, T.; VITORINO, A.C.T.; CARVALHO, D.F. de. Atributos físicos, químicos e erosão entressulcos sob chuva simulada, em sistemas de plantio direto e convencional. Engenharia Agrícola, Jaboticabal, v.25, n.1, p.144-153, 2005 a.

SILVA, F.F.P.; SCHAEFER, C.E.G.R.; AMORIM, R.S.S.; PAIVA, K.W.N. Efeito da cobertura nas perdas de solo em um Argissolo Vermelho-Amarelo utilizando simulador de chuva. Engenharia Agrícola, Jaboticabal, v.25, n.2, p.409-19, 2005b.

SILVA, A.M.; SILVA, M.L.N.; CURI, N.; LIMA, J.M.; AVANZI, J.C.; FERREIRA, M.M. Perdas de solo, água, nutrientes e carbono orgânico em Cambissolo e Latossolo sob chuva natural. Pesquisa Agropecuária Brasileira, Brasília, v.40, n.12, p.1223-1230, 2005c.

SINGER, J.M.; ANDRADE, D.F. Análise de dados longitudinais. SIMPÓSIO NACIONAL DE PROBABILIDADE ESTATÍSTICA, 7., 1986, Campinas. Anais... Campinas: UNICAMP, 1986. p.1-44.

WARNCKE, D.D.; BARBER, S.A. Diffusion of zinc in soil: I. The influence of soil moisture. Soil Science Society of America Proceedings, Madison, v.36, n.1, p.39-42, 1972. 